\title{
Improved Adsorption Capacity of Nannochloropsis sp. through Modification with Cetyltrimethylammonium Bromide on the Removal of Methyl Orange in Solution
}

\author{
Buhani $\mathbb{D}^{1},{ }^{1}$ Suharso $\mathbb{D}^{1},{ }^{1}$ Nurul Miftahza, ${ }^{1}$ Desy Permatasari, ${ }^{1}$ and Sumadi ${ }^{2}$ \\ ${ }^{1}$ Department of Chemistry, Faculty of Mathematic and Natural Sciences, University of Lampung, \\ Bandar Lampung 35145, Indonesia \\ ${ }^{2}$ Department of Electrical Engineering, Faculty of Engineering, University of Lampung, Bandar Lampung 35145, Indonesia
}

Correspondence should be addressed to Buhani; buhani_s@yahoo.co.id

Received 23 July 2021; Accepted 8 September 2021; Published 7 October 2021

Academic Editor: George Kyzas

Copyright ( 92021 Buhani et al. This is an open access article distributed under the Creative Commons Attribution License, which permits unrestricted use, distribution, and reproduction in any medium, provided the original work is properly cited.

\begin{abstract}
In this research, biomass modification of Nannochloropsis sp. with surfactant cetyltrimethylammonium bromide (CTAB) through a cation exchange reaction to produce adsorbent Nannochloropsis sp.-cetyltrimethylammonium bromide (AlgN-CTAB) has been carried out. Biomass modification of Nannochloropsis sp. by CTAB has been successfully carried out through confirmation from the analysis data produced by Fourier-transform infrared spectroscopy (FTIR) and scanning electron microscopy and energydispersive X-ray spectroscopy (SEM-EDX). AlgN-CTAB adsorbent has been tested for its adsorption ability against anionic dye of methyl orange (MO) in solution by way of a sequence of experiments by the batch method. The optimum conditions for MO removal from the solution occurred at an adsorbent quantity of $0.1 \mathrm{~g}, \mathrm{pH}$ of 5, and an interaction time of $60 \mathrm{~min}$. MO adsorption kinetic data by AlgN and AlgN-CTAB tended to take the kinetic model of pseudo-second-order (PSO) with PSO rate constant $\left(k_{2}\right)$ values of 0.56 and $2.17 \mathrm{~g} \mathrm{mg}^{-1} \mathrm{~min}^{-1}$, serially. The $\mathrm{MO}$ adsorption isotherm pattern by AlgN tends to take the Freundlich adsorption isotherm, whereas in AlgN-CTAB it follows the Langmuir and Dubinin-Radushkevich adsorption isotherms. The results of the adsorption-desorption of $\mathrm{MO}$ by AlgN-CTAB with 4 repetition cycles resulted in \% removal of $\mathrm{MO}>80 \%$. The AlgN-CTAB adsorbent can be used repeatedly and is very effective in absorbing $\mathrm{MO}$ in water.
\end{abstract}

\section{Introduction}

One of the major problems at this time is water contaminants which are caused by various activities of human life. Increasing technological and industrial advances so far have increased the release of unwanted contaminants like dyes, toxic metals, and pesticides into the surroundings $[1,2]$. This waste is generated from the by-products of processing industrial materials such as textiles, tannery, rubber, plastics, food, and cosmetics which can have an impact on the health of living things and their ecosystems $[3,4]$. One industry that is often found to produce dangerous contaminants like dyes resulting in toxic chemicals is the industry of textile. Dyestuff waste from the textile industry is a source of contaminants that are often found in the environment. Methyl orange (MO) is a coloring agent which is broadly utilized as a color- ing agent in several industrial fields like fabric, leather, paper, and pharmaceutical manufacturing. The majority of the artificial dyes and their derivation products own a high environmental effect, particularly in waters because of their wide application but with poor levels of sewage treatment [5]. Since the dye goes in the wastewater, the blend is more stabilized and complicated to break down because of its complex chemical composition [6]. Dyes are able to lead to a rise in biological oxygen demand (BOD) and can transmit waterborne diseases although they just produce a little share to the amount of organic charge in wastewater [7].

Methyl orange $\left(\mathrm{C}_{14} \mathrm{H}_{14} \mathrm{~N}_{3} \mathrm{NaO}_{3} \mathrm{~S}\right)$ is an anionic coloring agent usually produced by azo compounds and their descendant from the group of benzene. The benzene groups are very difficult to degrade because of their stable structure. Azo compounds are compounds that have the $-\mathrm{N}=\mathrm{N}$ group 
called the azo structure and are mostly present in waste. The compounds of azo in case overly lengthy in the surroundings are able to be a resource of illness due to their carcinogenic and mutagenic properties [8-11]. Therefore, it is necessary to reduce this dye in industrial waste, particularly in waste handling prior to its spread to the environment.

Treatment of dye waste such as MO was performed by way of various treatments consisting of coagulation, oxidation, flocculation, ion exchange, and adsorption [12-15]. The method that is quite effective and does not result in by-products which can damage the surroundings in treatment of waste containing dyes from various existing methods is the adsorption process $[16,17]$. However, the effectiveness in the adsorption process is strongly influenced by the selection of characteristic and the type of adsorbent to be implemented.

Currently, many adsorbents based on natural materials have been developed, such as algal biomass. Algal biomass is a very effective adsorbent for absorbing organic compound pollutants derived from dyes [18-20]. This is because algal biomass has functional groups that can act as active adsorption sites. From several studies that have been reported, algal biomass and the results of its modification with various supporting matrices are very effective in absorbing positively charged chemical compounds such as metal cations and cationic dyes [21-23], but it is less effective for absorbing anionic compounds. This happens because algal biomass contains active groups such as hydroxyl, amino, sulphate ions, and carboxyl $[23,24]$ which tend to be negatively charged.

In previous studies, the researchers had increased the biomass adsorption ability of Nannochloropsis sp. to absorb anionic dyes such as MO by modifying the algal biomass using cationic surfactants. Surface modification utilizing cationic surfactants has been shown to be an effective technology for increasing adsorbent adsorption capability. Cationic surfactants can make adsorbents rich in positive charges. Cationic surfactants that have been utilized effectively for an adsorbent surface modified by researchers were polyethylenimine (PEI), dodecylbenzyldimethylammonium chloride, and [3-(2-amino ethyl amino) propyl] trimethoxysilane (APTS) [25-27]. Algae biomass adsorbent is negatively charged by having an active group of alkaline or alkaline earth cation exchangers such as $\mathrm{Na}^{+}, \mathrm{K}^{+}$, or $\mathrm{Ca}^{2+}$ ions. The cations that are bound to the negative charge of algae biomass functional groups act like a counterweight to their charge which can be exchanged with other cations such as cationic surfactants $[3,28,29]$.

In this research, the adsorption characteristics of the adsorbent from the modified algal biomass of Nannochloropsis sp. with surfactant cetyltrimethylammonium bromide $(\mathrm{CTAB})(\mathrm{AlgN}-\mathrm{CTAB})$ were investigated which is cationic to adsorb MO dyes in solution. The increase in the adsorption ability of AlgN-CTAB on MO dyes can be determined by determining the kinetics and adsorption isotherm parameters. Thus, it can be obtained that modified algal biomass adsorbent is effective for application to absorb anionic dyes. Biomass modification increases the ability of algal biomass as a functional material that plays a role in absorbing toxic chemical compounds in chemical waste treatment.

\section{Materials and Methods}

2.1. Materials. Methyl orange and other chemicals required for the process of algal biomass modification and adsorption such as $\mathrm{NaCl}, \mathrm{CTAB}, \mathrm{HCl}, \mathrm{NaOH}$, citrate, and phosphate buffer are of analytical reagent (AR) grade and purchased based on the European Pharmacopoeia. Algae Nannochloropsis sp. was obtained from cultivation at the Center for Marine Cultivation in Lampung, Indonesia, and prepared into algal biomass in the Inorganic Chemistry Laboratory of FMIPA University of Lampung.

2.2. AlgN and AlgN-CTAB Preparation. Algae Nannochloropsis sp. was prepared to be biomass of Nannochloropsis sp. (AlgN) by drying it to air up to $72 \mathrm{~h}$ and in an oven at $40^{\circ} \mathrm{C}$ for $3 \mathrm{~h}$ [2]. Furthermore, $30 \mathrm{~g}$ of $\mathrm{AlgN}$ was reacted with $400 \mathrm{~mL}$ of $1 \mathrm{M} \mathrm{NaCl}$ solution in a $500 \mathrm{~mL}$ Erlenmeyer flask. After that, the solution was stirred with a shaker for 1 hour. The solution was then kept for 1 day and filtered. The solid produced was cleaned using $\mathrm{H}_{2} \mathrm{O}$ to neutral $\mathrm{pH}$ and dried at $25^{\circ} \mathrm{C}$ to give $\mathrm{AlgN}-\mathrm{Na}$. Then, $5 \mathrm{~g}$ of $\mathrm{AlgN}-\mathrm{Na}$ was reacted with $500 \mathrm{~mL} \mathrm{CTAB}$ and stirred for $4 \mathrm{~h}$ using a magnetite stirrer at $50^{\circ} \mathrm{C}$. The solid produced was neutralized by deionized water, dried at room temperature, and ground by a grinder to be fine with a 100 -mesh size to produce AlgN-CTAB.

2.3. Characterization of $A \lg N$ and $A \lg N-C T A B$. Characterization of AlgN and AlgN-CTAB was undertaken to analyze the appearance of functional groups by Fourier-transform infrared spectroscopy (FTIR) (Shimadzu Prestige-21 IR, Japan), while identification of surface morphology and elemental constituents was done by scanning electron microscopy with energy-dispersive X-ray spectroscopy (SEMEDX) (FEI Inspect-S50, USA).

2.4. Analysis of the Point of Zero Charge $\left(\mathrm{pH}_{p z c}\right)$ Adsorbent. A total of $0.05 \mathrm{~g}$ of adsorbent was put into each beaker glass continued by adding $10 \mathrm{~mL}$ of $0.1 \mathrm{M} \mathrm{NaNO}_{3}$. Furthermore, each solution $\mathrm{pH}$ was arranged with a range between 3 and 12. The $\mathrm{pH}$ adjustment was done by the addition of $0.1 \mathrm{M}$ hydrochloric acid for acidic conditions and $0.1 \mathrm{M}$ sodium hydroxide for alkaline conditions. The solution was stirred up to $24 \mathrm{~h}$, and the last $\mathrm{pH}$ for each solution was observed [21].

2.5. Batch Adsorption Experiment. The ability of the AlgN and $\mathrm{AlgN}-\mathrm{CTAB}$ adsorbents to absorb $\mathrm{MO}$ anionic dyes was investigated by studying the impact of AlgN-CTAB dose, contact time, $\mathrm{pH}$, concentration variations, and the ability to reuse adsorbent. A total of $1 \mathrm{~g} \mathrm{~L}^{-1}$ of stock solution of MO was made and further applied to result in the standard solution and initial concentration $\left([\mathrm{MO}]_{\mathrm{o}}\right)$ by diluting the stock solution accordingly. All experiments were undertaken at temperatures of $27^{\circ} \mathrm{C}$. In the adsorbent dose determination experiment, $25 \mathrm{~mL}$ of $[\mathrm{MO}]_{\mathrm{o}}=10 \mathrm{mg} \mathrm{L}^{-1}$ was reacted to the adsorbent with a weight varying between 0.05 and $0.25 \mathrm{~g}$. Furthermore, the optimum adsorbent dose was used in the next adsorption experiment. In the $\mathrm{pH}$ effect experiment, $[\mathrm{MO}]_{\mathrm{o}}$ was prepared at a $\mathrm{pH}$ varying from 3 to 12. The optimum $\mathrm{pH}$ obtained was used in the experiment 


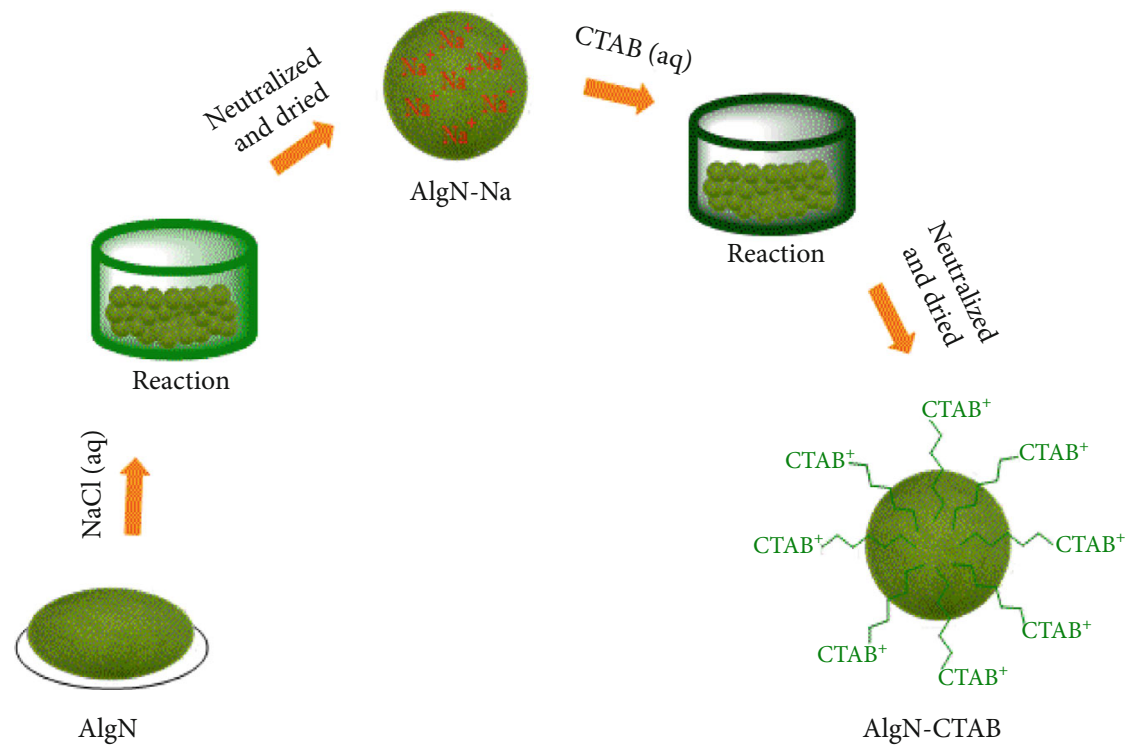

Figure 1: Adsorbent AlgN-CTAB preparation scheme.

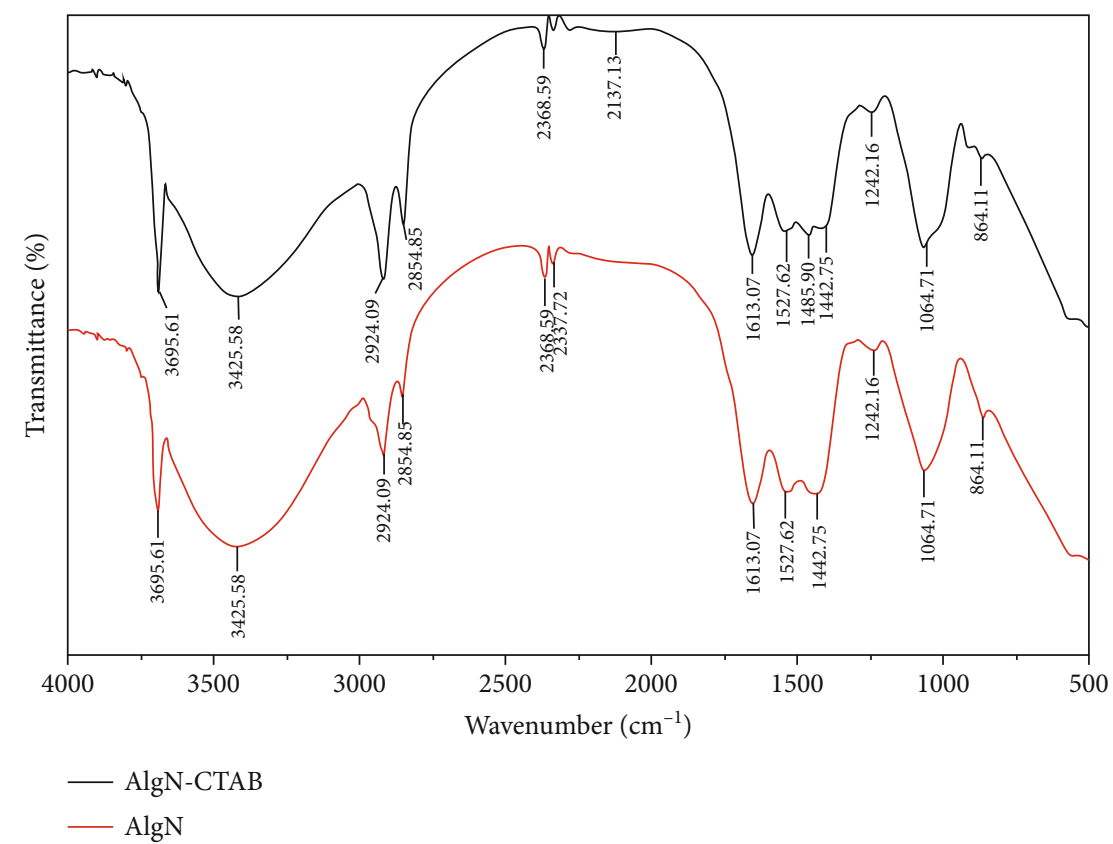

Figure 2: IR spectra of AlgN and AlgN-CTAB.

of contact time with time variations between 15 and $120 \mathrm{~min}$. For the concentration effect experiment, the experiments were carried out at optimum $\mathrm{pH}$ and time conditions with $[\mathrm{MO}]_{\mathrm{o}}=0-300 \mathrm{mg} \mathrm{L}^{-1}$. The $[\mathrm{MO}]$ obtained after the adsorption process was explored by a UV-Vis spectrophotometer with a maximal wavelength of $465 \mathrm{~nm}$ (UV-Vis spectrophotometer (Agilent Cary 100, U.S.A)). All experiments in this research were carried out in 3 repetitions. Furthermore, the $[\mathrm{MO}]$ dye adsorbed was identified by calculating the MO dye bound per unit mass of adsorbent and the percentage of MO removal was determined using

$$
\begin{aligned}
q_{\mathrm{e}} & =\frac{\left(C_{\mathrm{o}}-C_{\mathrm{e}}\right)}{m} \times V, \\
q_{t} & =\frac{\left(C_{\mathrm{o}}-C_{t}\right)}{m} \times V, \\
R(\%) & =\frac{\left(C_{\mathrm{o}}-C_{t}\right)}{C_{\mathrm{o}}} \times 100,
\end{aligned}
$$




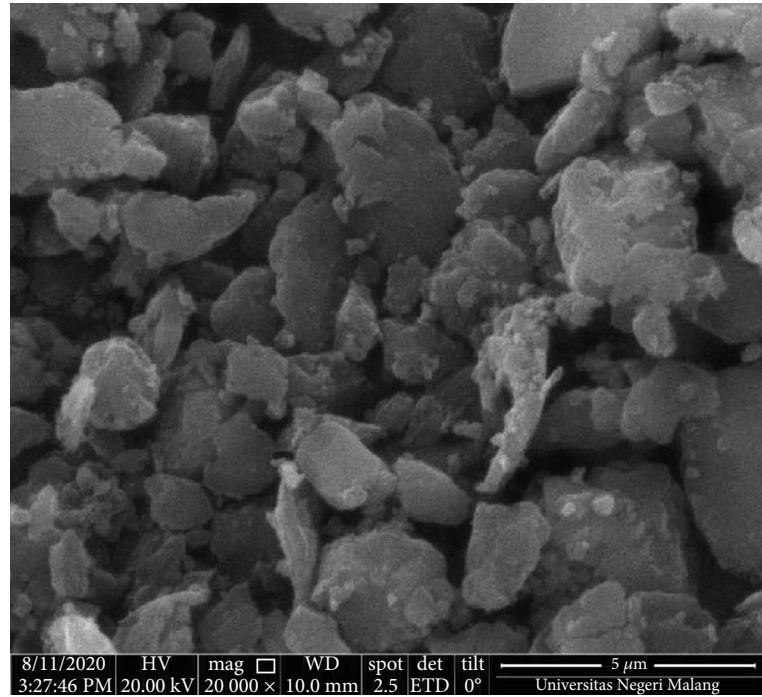

(a)

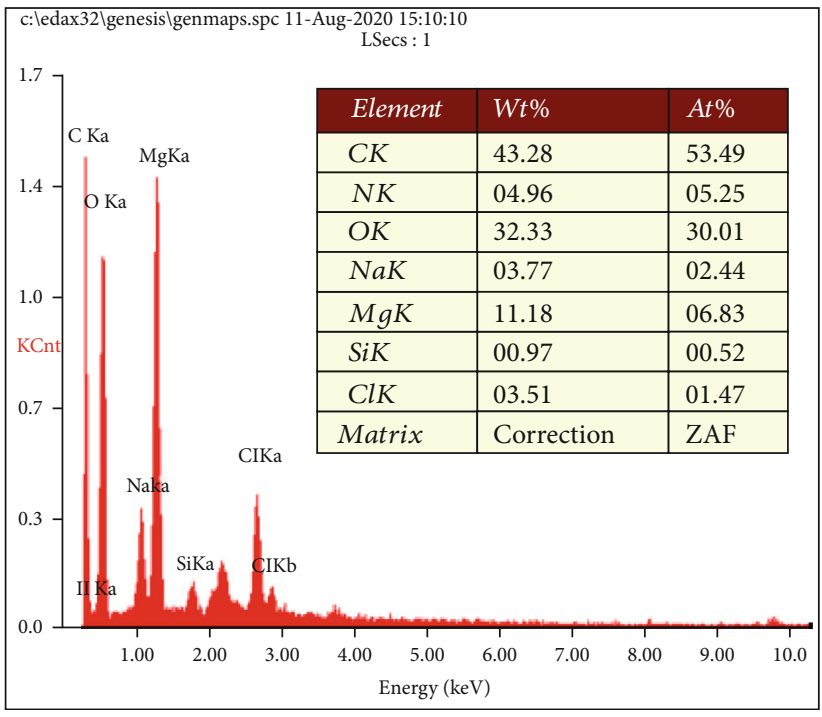

(c)

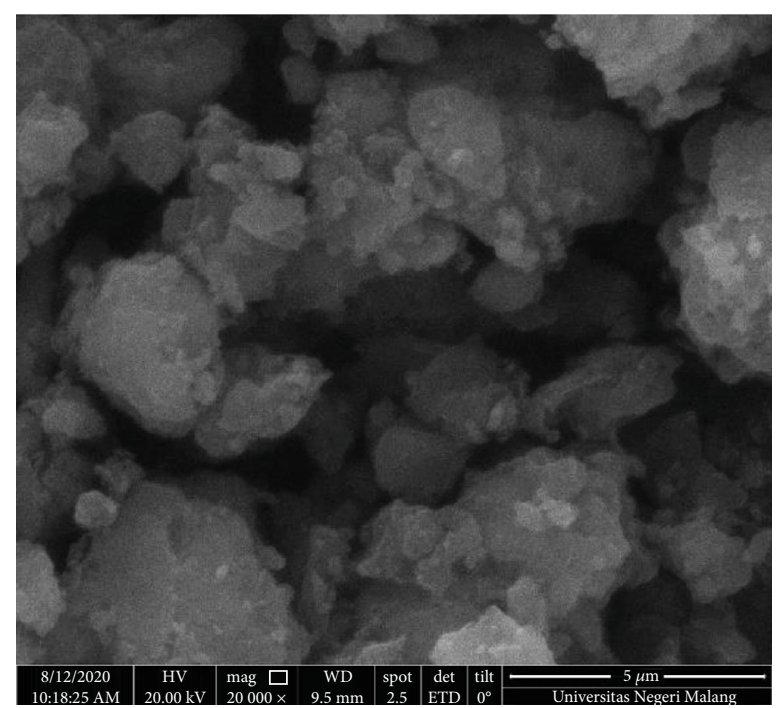

(b)

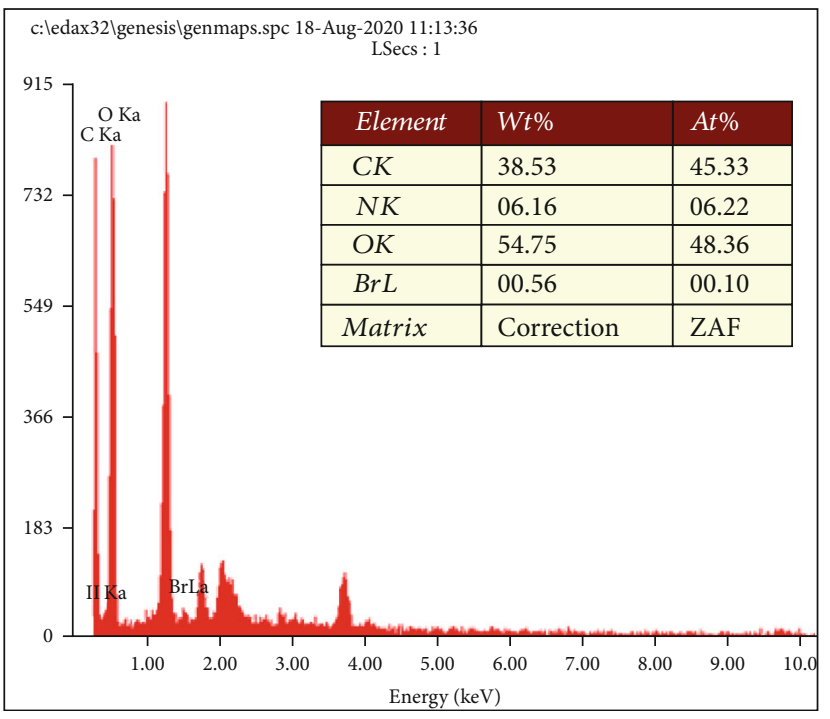

(d)

Figure 3: SEM-EDX of (a, c) AlgN and (b, d) AlgN-CTAB.

where $C_{\mathrm{o}}$ is the concentration in the initial state, $C_{\mathrm{e}}$ is the concentration at equilibrium, $C_{t}$ is the concentration at a certain time $t$ of [MO] $\left(\mathrm{mg} \mathrm{L}^{-1}\right), m$ is the adsorbent mass (g), $V$ is the solution volume (L), $q$ is the amount of $\mathrm{MO}$ bound per unit mass $\left(\mathrm{mgg}^{-1}\right)$, and $R$ is the percentage of MO removal.

The adsorption data of $\mathrm{MO}$ adsorbed by AlgN and AlgN-CTAB were analyzed by determining the correlation between the amount of MO in the adsorbed solution experimentally and the estimation results with the adsorption isotherm of Langmuir (AIML), Freundlich (AIMF), DubininRadushkevich (AIMDR), and Temkin (AIMT). The evaluation was carried out by determining the root mean squared error (RMSE) and chi-square test $\left(\chi^{2}\right)[30,31]$.

2.6. Regeneration. Reuse of the AlgN-CTAB adsorbent was observed by performing adsorption experiments at optimum conditions. The MO dye that had been adsorbed by AlgN$\mathrm{CTAB}$ was removed again using an eluent in the form of $0.1 \mathrm{M}$ hydrochloric acid $(50 \mathrm{~mL})$. The adsorptiondesorption processes were undertaken several times, until the $\%$ MO adsorption was $<80 \%$.

\section{Results and Discussion}

3.1. Preparation and Characterization of Adsorbents. AlgN$\mathrm{CTAB}$ is an adsorbent based on the algal biomass of Nannochloropsis sp. modified by cation exchange reaction using $\mathrm{CTAB}$ surfactant. The procedure for making AlgN-CTAB is shown in Figure 1.

AlgN-CTAB was made by uniforming the charge with excess $\mathrm{Na}^{+}$cations using $\mathrm{NaCl}$ solution which is aimed at increasing the cation exchange capacity [5]. Ions of $\mathrm{Na}^{+}$contained in the algal biomass of Nannochloropsis sp. were 
replaced with $C T A B$ surfactant via a cation exchange reaction which produces AlgN-CTAB. Then, the AlgN-CTAB adsorbent was characterized by FTIR for functional group determination and SEM-EDX for surface morphology and elemental investigation.

Figure 2 illustrates that the IR spectrum of AlgN indicates an absorption band at wave number $1613.07 \mathrm{~cm}^{-1}$ identifying a typical $\mathrm{C}=\mathrm{O}$ absorption of a carboxylic acid. In addition, the absorption appears at the wave numbers around 2854.85 and $2924.09 \mathrm{~cm}^{-1}$, respectively, obtained from the $-\mathrm{CH}_{2}$ symmetrical stretching and asymmetry vibration of a carbon chain (aliphatic) $[32,33]$. The absorption at wave number $3695.61 \mathrm{~cm}^{-1}$ comes from the overlap of the - $\mathrm{O}-\mathrm{H}$ and $-\mathrm{N}-\mathrm{H}$ groups. In AlgN-CTAB, all characteristic IR spectra of the algal biomass of Nannochloropsis sp. appeared with the addition of a new absorption at a wavelength of $1465.90 \mathrm{~cm}^{-1}$ indicating the existence of the $\mathrm{CH}$ group which is the methyl group from CTAB [34-36].

The surface morphology of AlgN-CTAB was explored with SEM coupled with the determination of constituent elements using EDX. SEM characterization provides main information on the surface morphology of adsorbent. In Figure 3(b), it could be investigated that, in AlgN-CTAB, the surface morphology area is wider than that in AlgN (Figure 3(a)) and there are sticky grains which indicate the existence of molecules of CTAB on the surface layer of the algal biomass of Nannochloropsis sp. Cetyltrimethylammonium bromide molecules do not enter the algae but only cover the algal cell walls after surfactant modification [5]. The presence of CTAB on the AlgN surface is also supported by the EDX data in Figure 3(d) which shows the appearance of the $\mathrm{Br}$ element derived from CTAB in AlgN-CTAB that did not previously appear in the EDX data from AlgN (Figure 3(c)).

3.2. Impact of Adsorbent Dosage on Adsorption. Dosage of adsorbent is one of the main parameters in deciding the effective adsorption conditions so that it is economically feasible to use adsorbents for certain purposes. In this research, the impact of the adsorbent dosage was studied using AlgNCTAB in the range $0.1-0.5 \mathrm{~g}$ in $10 \mathrm{mg} \mathrm{L}^{-1}[\mathrm{MO}](25 \mathrm{~mL})$ as displayed in Figure 4.

Figure 4 illustrates the impact of the adsorbent dose on the absorption percentage of MO dye which increases by the rise in the adsorbent dosage and the optimum at the particular adsorbent dosage used. This shows that raising the dose of adsorbent applied increases the amount of adsorption sites to absorb MO dye, but the increase in the amount of MO adsorbed is also limited by the amount of adsorbate concentration used. It may be seen in Figure 4 that the opti$\mathrm{mal} \mathrm{AlgN}$ dose is $0.1 \mathrm{~g}$. This dose is used for further trials.

3.3. Impact of Solution Acidity on Adsorption. In this experiment, the impact of $\mathrm{pH}$ of $\mathrm{MO}$ dye solution on AlgN-CTAB adsorbent was studied in the $\mathrm{pH}$ range between 3 and 12 . Figure 5 explains that the change in the $\mathrm{pH}$ value of the $\mathrm{MO}$ dye solution has no impact on the percentage of $\mathrm{MO}$ adsorbed by AlgN-CTAB. From these data, it appears that the removal efficiency of $\mathrm{MO}$ solution in the $\mathrm{pH}$ range 3-

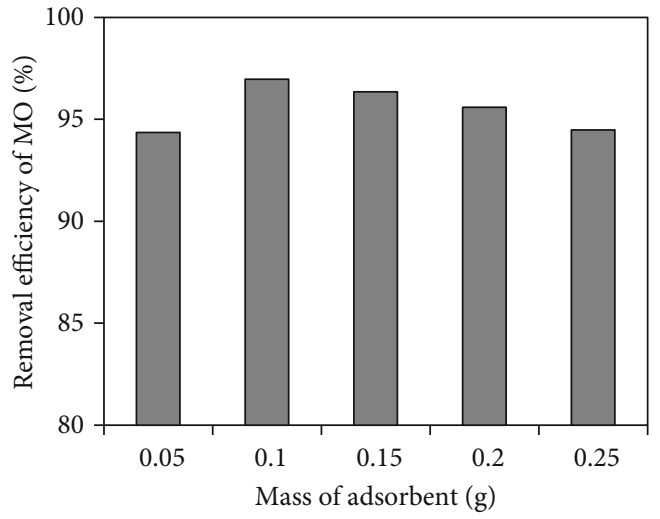

FIgURE 4: Impact of adsorbent mass on sorption of MO dye on $\operatorname{AlgN}-\mathrm{CTAB}\left([\mathrm{MO}]_{\mathrm{o}}=10 \mathrm{mg} \mathrm{L}^{-1}\right.$, interaction time $=60 \mathrm{~min}$, and $\left.T=27^{\circ} \mathrm{C}\right)$.

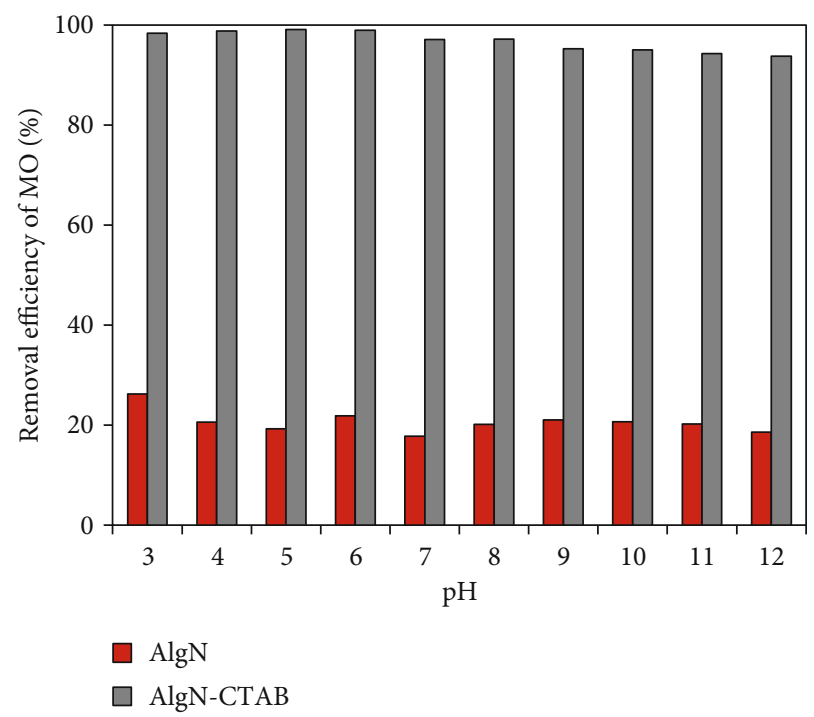

FIgURe 5: Impact of $\mathrm{pH}$ on the removal of MO dye using AlgN and AlgN-CTAB $\quad$ (adsorbent mass $=0.1 \mathrm{~g}, \quad[\mathrm{MO}]_{\mathrm{o}}=10 \mathrm{mg} \mathrm{L}^{-1}$, interaction time $=60 \mathrm{~min}$, and $T=27^{\circ} \mathrm{C}$ ).

12 is more than $96 \%$. This can occur because the interaction between MO dye and AlgN-CTAB occurs through an electrostatic interaction mechanism among the positive charges of AlgN-CTAB and MO dye [37, 38]. The existence of biomass modification with $\mathrm{CTAB}$ has increased its ability to absorb anionic dyes. This is supported by \% MO which is adsorbed at very low AlgN in all $\mathrm{pH}$ ranges. This happens because $\mathrm{AlgN}$ is dominated by active groups that are negatively charged, so there is repulsion with MO dye which is negatively charged; as a result, the adsorption process is not optimal.

Increasing the $\mathrm{pH}$ value $>6$ indicates a few reductions in adsorption; this is because at higher $\mathrm{pH}$, the increased $\mathrm{OH}^{-}$ ion level will compete with $\mathrm{MO}$ dye which is anionic to occupy the active site of the positively charged AlgNCTAB (Figure 5) [37]. This is also supported by the $\mathrm{pH}_{\mathrm{pzc}}$ value of AlgN-CTAB which is 8.0 (Figure 6). The surface charge of the adsorbent is positive as $\mathrm{pH}<\mathrm{pH}_{\mathrm{pzc}}$, whereas 


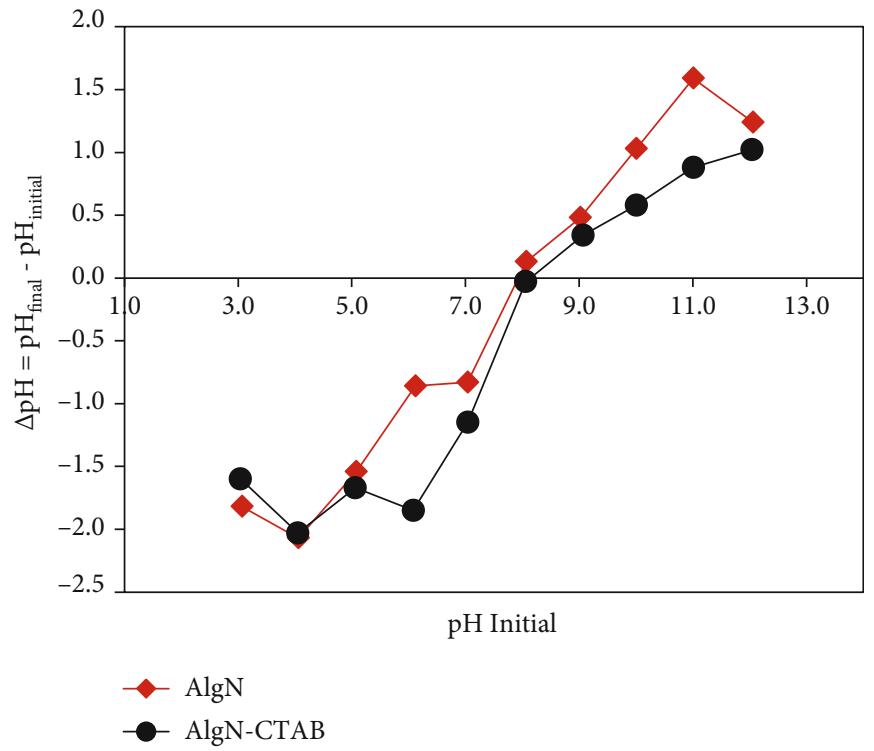

FIgURE 6: Investigation of $\mathrm{pH}_{\mathrm{pzc}}$ of the AlgN and AlgN-CTAB.

the surface charge is negative as $\mathrm{pH}>\mathrm{pH}_{\mathrm{pzc}}$ [39]. Thus, at $\mathrm{pH}<8$, the AlgN-CTAB surface is positively charged, making it very effective at absorbing $\mathrm{MO}$ dyes that are negatively charged. Based on these considerations, the next experiment was carried out with a $\mathrm{pH}$ of 5 . At that $\mathrm{pH}$, the AlgN-CTAB adsorbent surface charge is positive while the MO dye adsorbent charge is negative. Thus, under these conditions, the interaction between AlgN-CTAB and MO dye that occurs electrostatically is more optimal.

3.4. Impact of Contact Time on Adsorption. In order to observe the impact of contact time, adsorption experiments were done by the MO dye solution at varying contact times between 0 and 120 minutes. The resulting adsorption data is illustrated in Figure 7, and it shows that more than $94 \%$ of MO dye was absorbed by AlgN-CTAB in the initial 15 minutes and the adsorption stability period was reached at $60 \mathrm{~min}$. Increasing the contact time of more than 60 minutes apparently did not increase the percentage of $\mathrm{MO}$ adsorbed by $\mathrm{AlgN}$ and $\mathrm{AlgN}-\mathrm{CTAB}$, by about 24.56 and $98.69 \%$, respectively. Therefore, the equilibrium time was used for further experiments.

3.5. Adsorption Kinetics. Adsorption kinetic models are applied to identify the dominant mechanisms determining process of adsorption like chemical reactions and mass transfer. In this study, the pseudo-first-order (PFO), pseudo-second-order (PSO), and intraparticle diffusion (IPD) models have been used to explore the adsorption facts shown in Figure 7.

The PFO kinetic model presumes that the adsorption rate of the filled sites is combined by the amount of unfilled sites described by the next linear equation [40].

$$
\log \left(q_{\mathrm{e}}-q_{t}\right)=\log q_{\mathrm{e}}-\frac{k_{1}}{2.303} t
$$

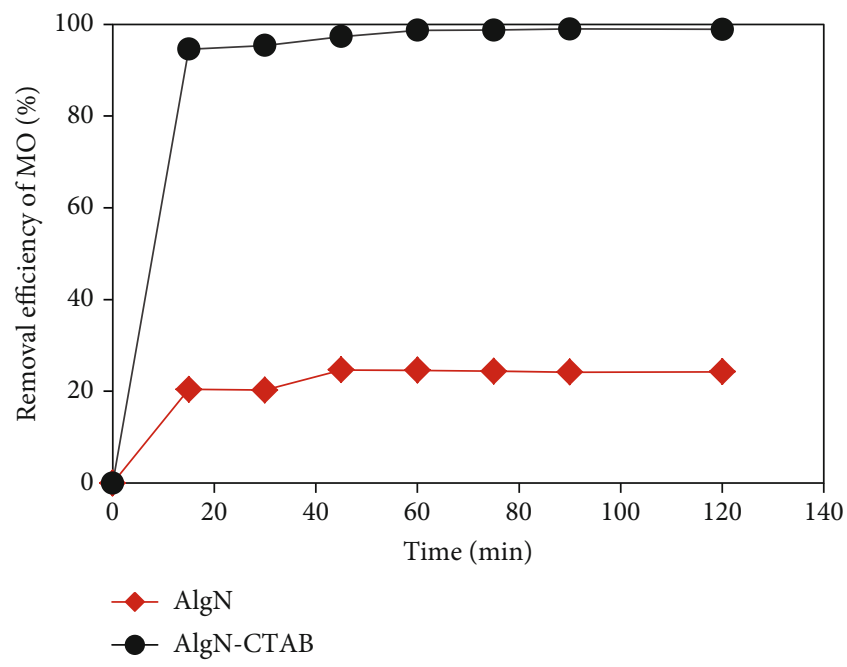

FIgURe 7: Impact of interaction time on the removal of $\mathrm{MO}$ dye using $\mathrm{AlgN}$ and $\mathrm{AlgN}-\mathrm{CTAB}$ (adsorbent mass $=0.1 \mathrm{~g},[\mathrm{MO}]_{\mathrm{o}}=10$ $\mathrm{mg} \mathrm{L}^{-1}, \mathrm{pH}=5$, and $\mathrm{T}=27^{\circ} \mathrm{C}$ ).

The PSO kinetic model supposes that the capacity of adsorption is comparable to the amount of active sites that existed on the adsorbent using a linear equation.

$$
\frac{t}{q_{t}}=\frac{1}{k_{2} q_{\mathrm{e}}^{2}}+\frac{t}{q_{\mathrm{e}}},
$$

where $q_{t}$ and $q_{\mathrm{e}}\left(\mathrm{mgg}^{-1}\right)$ represent the total MO dye adsorption capacity at period $t$ and at stability, serially, and $k_{1}$ and $k_{2}$ describe the rate constants of the PFO and PSO, serially. The facts of data analysis from the two adsorption kinetic patterns are described in Figure 8 and listed in Table 1.

The use of the Morris-Weber kinetic model [41, 42] assumes that the diffusion process of adsorbates such as MO dye to the adsorbent is controlled by a physical 


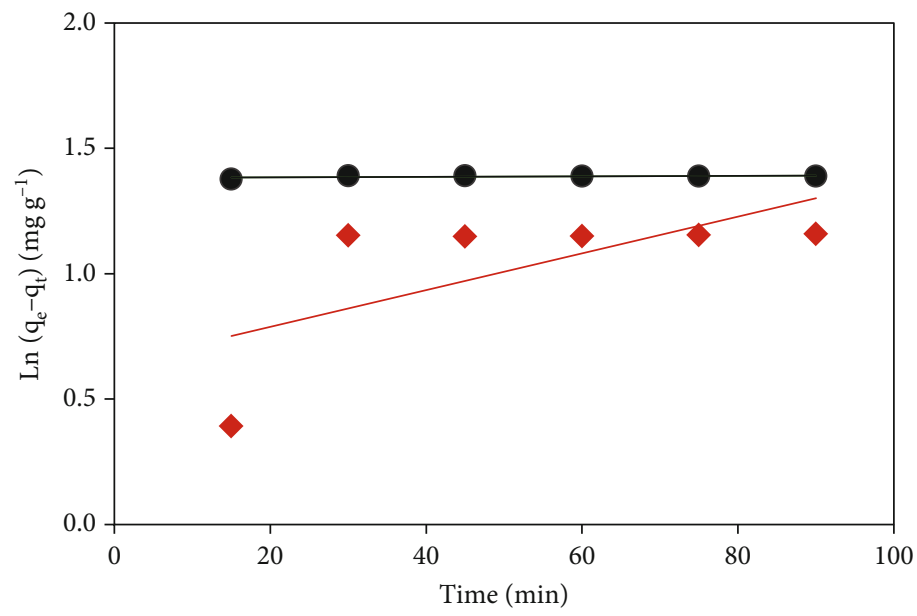

- AlgN

- AlgN-CTAB

(a)

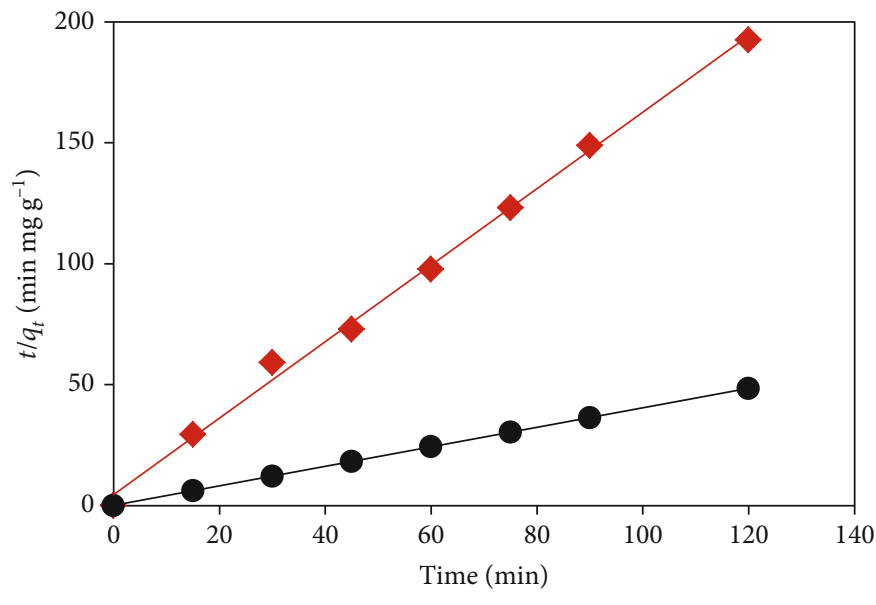

AlgN

- $\mathrm{AlgN}-\mathrm{CTAB}$

(b)

Figure 8: Linearized (a) PFO and (b) PSO kinetic models on adsorption of MO dye.

TABle 1: Kinetic parameters for the adsorption of MO dye on AlgN and AlgN-CTAB.

\begin{tabular}{lcccccr}
\hline Adsorbents & \multicolumn{2}{c}{ PFO } & \multicolumn{2}{c}{ PSO } \\
& $\begin{array}{c}q_{\mathrm{e}(\exp )} \\
\left(\mathrm{mg} \mathrm{g}^{-1}\right)\end{array}$ & $\begin{array}{c}q_{\mathrm{e}(\mathrm{cal})} \\
\left(\mathrm{mg} \mathrm{g}^{-1}\right)\end{array}$ & $\begin{array}{c}k_{1} \\
\left(\mathrm{~min}^{-1}\right)\end{array}$ & $R^{2}$ & $\begin{array}{c}q_{\mathrm{e}(\mathrm{cal})} \\
\left(\mathrm{mg} \mathrm{g}^{-1}\right)\end{array}$ & $\begin{array}{c}k_{2} \\
\left(\mathrm{~g} \mathrm{mg}^{-1} \mathrm{~min}^{-1}\right)\end{array}$ \\
\hline AlgN & 0.609 & 0.504 & 0.001 & 0.324 & 0.632 & 0.557 \\
AlgN-CTAB & 2.474 & 2.960 & 0.642 & 0.473 & 2.477 & 2.173 \\
\hline
\end{tabular}

mechanism that leads to a main part in the process of adsorption as described in

$$
q_{t}=k_{\mathrm{id}} t^{0.5}+C
$$

where $k_{\mathrm{id}}\left(\mathrm{mgg}^{-1} \mathrm{~min}^{-0.5}\right)$ expresses the rate constant of IPD and the value of $C\left(\mathrm{mg} \mathrm{g}^{-1}\right)$ describes a constant representing resistance to mass transfer in limit layer. $k_{\mathrm{id}}$ and $C$ were computed by the slope and intercept of stripes that resulted from the graph of $q_{t}$ against $t^{0.5}$.

Data in Figure 7 were also analyzed with an IPD model that can describe the process of diffusion from the objects absorbed by the adsorbent which could be applied to simulate data of kinetics [43]. The results of the analysis are described in Figure 9 and listed in Table 2. It may be observed in Figure $8(\mathrm{c})$ that the entire plots contain two 


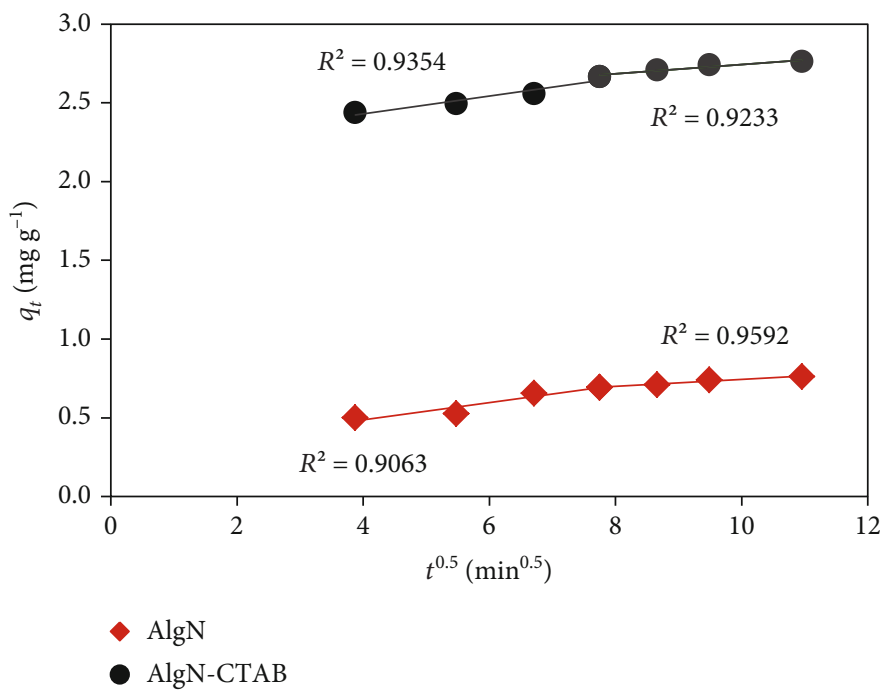

Figure 9: Linearized kinetic model of IPD on adsorption of MO dye.

TABLE 2: Intraparticle diffusion model for MO dye adsorption onto AlgN and AlgN-CTAB.

\begin{tabular}{lccccrr}
\hline \multirow{2}{*}{ Adsorbent } & \multicolumn{3}{c}{ Initial linear portion } & \multicolumn{3}{c}{ Second linear portion } \\
& $k_{i 1}\left(\mathrm{mg} \mathrm{g}^{-1} \mathrm{~min}^{0.5}\right)$ & $C_{1}\left(\mathrm{mg} \mathrm{g}^{-1}\right)$ & $R_{1}^{2}$ & $k_{i 2}\left(\mathrm{mg} \mathrm{g}^{-1} \min ^{0.5}\right)$ & $C_{2}\left(\mathrm{mg} \mathrm{g}^{-1}\right)$ & 0.267 \\
\hline AlgN & 0.054 & 0.274 & 0.906 & 0.022 & 0.959 \\
AlgN-CTAB & 0.057 & 2.203 & 0.935 & 0.029 & 2.450 \\
\hline
\end{tabular}

linear sections. These patterns show that there is over one adsorption model linked. The initial linear part covers time of adsorption of 0-60 minutes representing the external transfer of mass. The next linear part covers time of adsorption of 60-120 minutes, indicating a pattern depicting intraparticle diffusion. The second linear part does not pass through the origin $(C \neq 0)$; this indicates that intraparticle diffusion is not only stage of rate control and external mass transfer but it also occurs in unison [41, 42].

The results of the analysis of the $\mathrm{MO}$ adsorption data by AlgN and AlgN-CTAB using the PFO, PSO, and IPD models are linearly shown in Figures 8 and 9 as well as in Tables 1 and 2. If the value of linear correlation coefficient $\left(R^{2}\right)$ of the PFO and PSO kinetic models is compared, the $R^{2}$ value in the PSO is greater than that in the PFO kinetic model (Table 1). This indicates that the MO adsorption by AlgN and AlgN-CTAB tends to follow the PSO kinetic model. In addition, the kinetic rate constant of PSO $\left(k_{2}\right) \mathrm{MO}$ by AlgN-CTAB is greater than that by AlgN (Table 1). This can be explained by the modification of the algal biomass of Nannochloropsis sp. with cationic surfactants such as $\mathrm{CTAB}$ which can make the adsorbent rich in positive charges [44]. Thus, the MO molecule which is anionic is very suitable for the positively charged AlgN-CTAB conditions for the occurrence of electrostatic interactions. In AlgN, the adsorbent surface is dominated by active sites with negative charges originating from the algal biomass functional group so that there will tend to be a repulsive force with MO molecules which results in a low amount of MO adsorbed.
According to the investigation in Figure 9, there are two stages that describe the transfer of MO from the solution to the adsorbent outer surface and further directional diffusion of the MO to active sites of the adsorbent through pore cavities and active groups, respectively. The mechanism of adsorption is able to be described in two dissimilar manners, namely, diffusion through adsorbent pores and electrostatic interactions in the existence of positive charges of functional groups from the modification of AlgN to AlgN-CTAB [45]. This is in line with the data analysis of the PSO kinetics discussed earlier.

3.6. Impact of MO Concentration on Adsorption. To determine the impact of [MO] on the adsorption capacity of $\mathrm{AlgN}$ and AlgN-CTAB and to learn the equilibrium of the adsorption process, adsorption tests at various $[\mathrm{MO}]_{\mathrm{o}}=0-$ $300 \mathrm{mg} \mathrm{L}^{-1}$ were carried out. This experimentation was performed in $25 \mathrm{~mL}$ of [MO], and other experimental situations like adsorbent mass, initial $\mathrm{pH}$, and contact time were at optimum conditions. Algal biomass modification by Nannochloropsis sp. with $\mathrm{CTAB}$ has increased the amount of $\mathrm{MO}$ dye adsorbed (Figure 10(b)).

The increase in $q_{\text {exp }}$ occurred in line with the increase in $[\mathrm{MO}]_{\mathrm{o}}$ used. It may be explained that raising the initial concentration of the adsorbate will increase the driving force which decreases the mass transfer resistance between the adsorbent and the adsorption medium. In addition, the increase in $q_{\exp }$ is also related to the competition between active adsorption sites available on the adsorbent [46, 47]. 


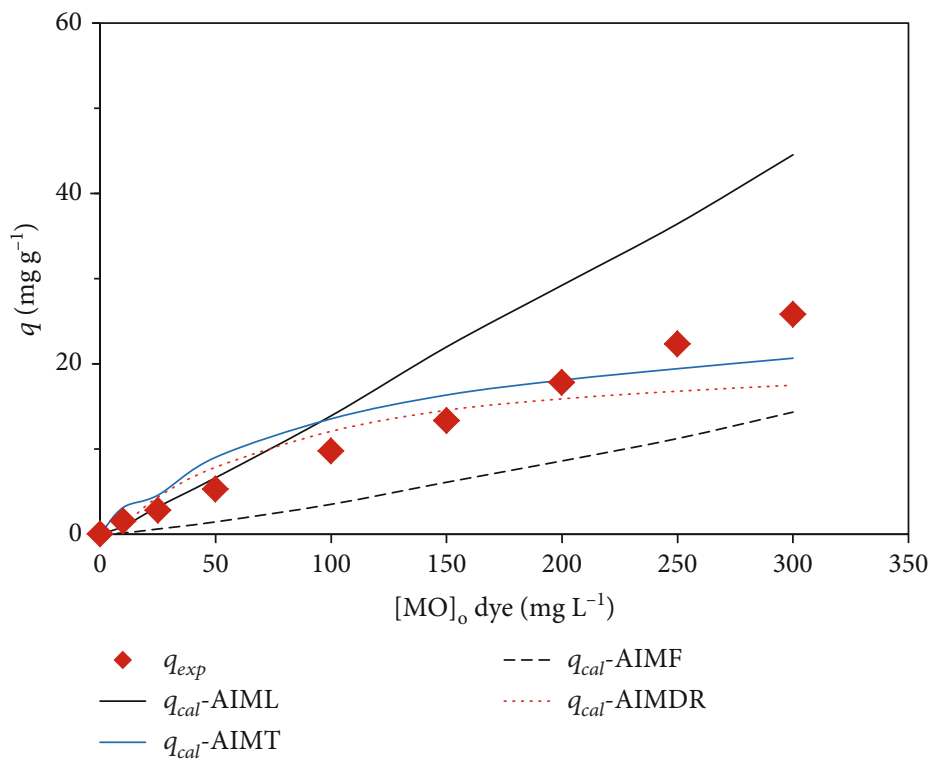

(a)

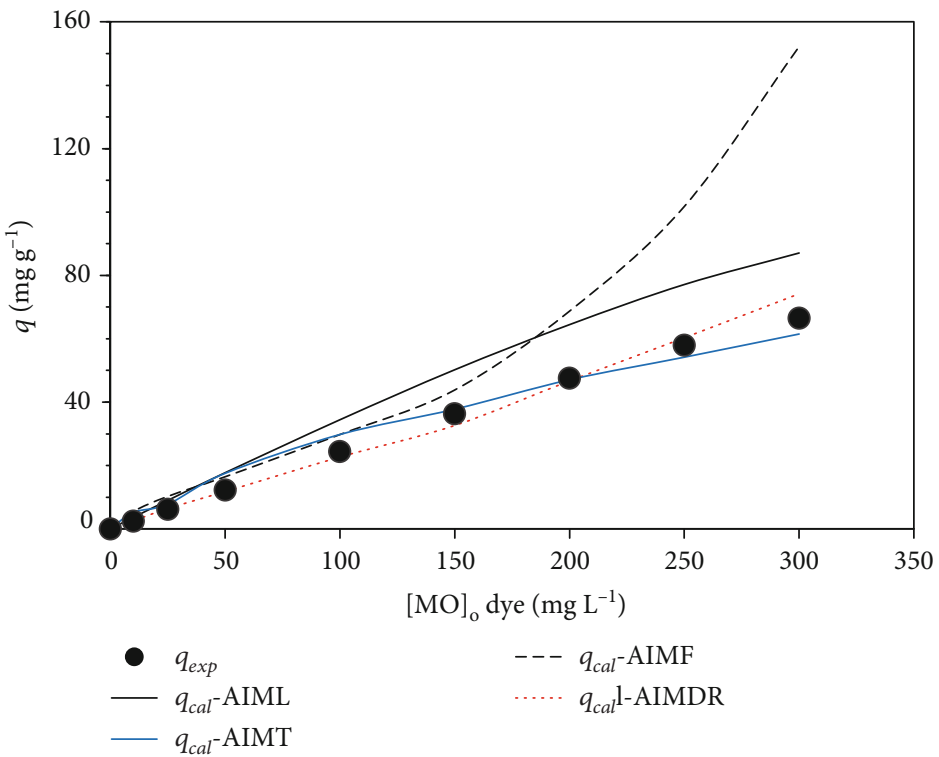

(b)

FIgURE 10: The impact of $[\mathrm{MO}]_{\mathrm{o}}$ on the amount of $\mathrm{MO}$ adsorbed in (a) AlgN and (b) AlgN-CTAB based on experimental results $\left(q_{\text {exp }}\right)$ and estimation using the AIML, AIMF, AIMDR, and AIMT equations.

The amount of $\mathrm{MO}$ absorbed per gram $\left(q_{\mathrm{exp}}\right)$ of AlgN and AlgN-CTAB vs. $[\mathrm{MO}]_{\mathrm{o}}$ is displayed in Figure 10.

3.7. Adsorption Isotherm. Adsorption isotherm data is the main indicator to know in explaining the adsorption process. The isotherm shows the relationship between the amounts of MO bound by the adsorbent at fixed temperature. The adsorption isotherm patterns that are often utilized in deciding the adsorption parameters are the Langmuir and Freundlich adsorption isotherm models (AIML and AIMF). In addition, the Dubinin-Radushkevich and Temkin models (AIMDR and AIMT) can also be used because they may present extra information consisting of energy and mecha- nism of adsorption. The products of the $\mathrm{MO}$ adsorption information analysis by AlgN and AlgN-CTAB are shown in Table 3. The relationship between $[\mathrm{MO}]_{\mathrm{o}}$ and the amount of MO dye bound in AlgN and AlgN-CTAB is according to experimental results $\left(q_{\mathrm{exp}}\right)$, and estimates using adsorption equations of AIML, AIMF, AIMDR, and AIMT can be seen in Figure 10.

The AIML presumes that, on the adsorbent surface, there is an amount of active sites which is proportionate toward the uniform surface area of the adsorbent accompanied by a monolayer adsorption process $[48,49]$. The linear equation of AIML is displayed in Equation (5), while the AIMF is an empirical equation applied to multilayer 
TABle 3: Adsorption isotherm parameters of $\mathrm{MO}$ dye on AlgN and AlgN-CTAB.

\begin{tabular}{|c|c|c|c|}
\hline \multirow[b]{2}{*}{ Experiment } & \multicolumn{3}{|c|}{$\begin{array}{c}\text { AlgN } \\
\text { Parameters }\end{array}$} \\
\hline & $q_{\exp }\left(\mathrm{mg} \mathrm{g}^{-1}\right)$ & 25.776 & 66.422 \\
\hline \multirow{5}{*}{ AIML } & $q_{\mathrm{m}}\left(\mathrm{mgg}^{-1}\right)$ & 5.044 & 76.479 \\
\hline & $K_{L}\left(\mathrm{~L} \mathrm{mg}^{-1}\right)$ & 1.479 & 5.986 \\
\hline & $R^{2}$ & 0.702 & 0.999 \\
\hline & RMSE & 6.863 & 10.47 \\
\hline & $\chi^{2}$ & 24.284 & 26.145 \\
\hline \multirow{5}{*}{ AIMF } & $K_{F}\left(\left(\mathrm{mgg}^{-1}\right)\left(\mathrm{L} \mathrm{mg}^{-1}\right)^{1 / n}\right)$ & 2.037 & 16.376 \\
\hline & $n$ & 0.831 & 1.585 \\
\hline & $R^{2}$ & 0.988 & 0.955 \\
\hline & RMSE & 5.743 & 6.282 \\
\hline & $\chi^{2}$ & 17.218 & 7.525 \\
\hline \multirow{5}{*}{ AIMDR } & $q_{\mathrm{DR}}\left(\mathrm{mgg}^{-1}\right)$ & 20.186 & 106.933 \\
\hline & $B_{\mathrm{DR}} \times 10^{-6}$ & 2.524 & 7.333 \\
\hline & $R^{2}$ & 0.662 & 0.999 \\
\hline & RMSE & 3.639 & 3.043 \\
\hline & $x^{2}$ & 7.094 & 1.539 \\
\hline \multirow{5}{*}{ AIMT } & $b_{\mathrm{Te}} \times 10^{-2}\left(\mathrm{~J} \mathrm{~mol}^{-1}\right)$ & 2.435 & 5.223 \\
\hline & $a_{\mathrm{Te}} \times 10^{-2}\left(\mathrm{Lg}^{-1}\right)$ & 1.023 & 1.215 \\
\hline & $R^{2}$ & 0.832 & 0.967 \\
\hline & RMSE & 3.543 & 4.961 \\
\hline & $\chi^{2}$ & 2.128 & 4.133 \\
\hline
\end{tabular}

adsorption and heterogeneous system [50]. The linear equation of AIMF is shown in Equation (6).

$$
\begin{gathered}
\frac{1}{q_{\mathrm{e}}}=\frac{1}{q_{\mathrm{m}} K_{L} C_{\mathrm{e}}}+\frac{1}{q_{\mathrm{m}}}, \\
\log q_{\mathrm{e}}=\log K_{F}+\frac{1}{n} \log C_{\mathrm{e}} .
\end{gathered}
$$

The AIMDR has more universal assumptions than the AIML. The AIMDR presumes that the adsorption surface is not homogeneous [51]. The adsorption isotherm equation of this model in linear form is expressed in Equation (7). Meanwhile, the AIMT calculates the complete interaction between adsorbent and adsorbate. The main significant presumption of the AIMT is that the adsorption heat will reduce linearly by the increase in the adsorbent surface coverage [20]. The AIMT linear equation is observed in Equation (8).

$$
\begin{gathered}
\ln q_{\mathrm{e}}=q_{\mathrm{DR}}-2 B_{\mathrm{DR}} R T \ln \left(\frac{1+1}{C_{\mathrm{e}}}\right), \\
q_{\mathrm{e}}=\frac{R T}{b_{\mathrm{Te}}} \ln \left(K_{\mathrm{Te}} C_{\mathrm{e}}\right),
\end{gathered}
$$

where $q_{\mathrm{e}}\left(\mathrm{mg} \mathrm{g}^{-1}\right)$ presents the total of MO bound at condition of equilibrium, $q_{\mathrm{m}}\left(\mathrm{mgg}^{-1}\right)$ represents the maximal

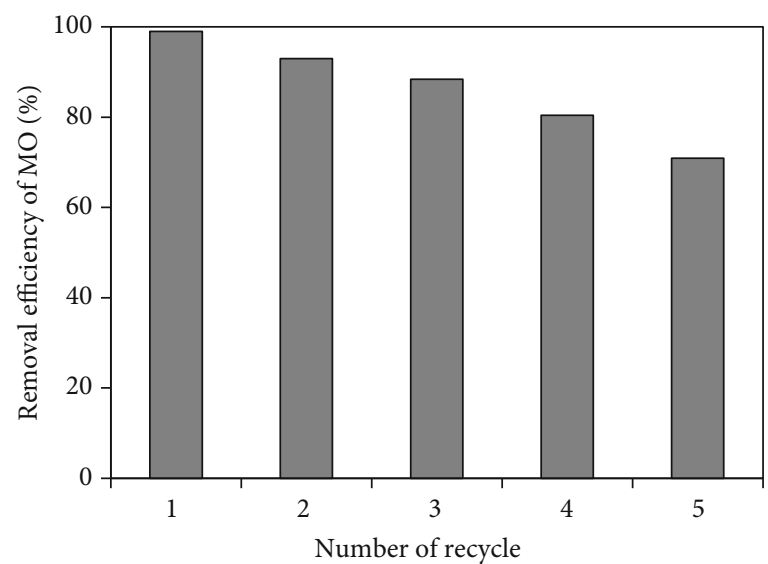

FIGURE 11: Reusability number efficiency of the adsorption of MO on AlgN-CTAB.

adsorption capacity of $\mathrm{MO}$ which indicates the monolayer adsorbent ability to absorb $\mathrm{MO}, C_{\mathrm{e}}\left(\mathrm{mg} \mathrm{L}^{-1}\right)$ belongs to the equilibrium [MO], and $K_{L}$ describes the equilibrium constant containing the binding site affinity $\left(\mathrm{L} \mathrm{mg}^{-1}\right) . K_{L}$ and $q_{\mathrm{m}}$ may be evaluated from the linear equation graph of log $1 / q_{\mathrm{e}}$ versus $C_{\mathrm{e}}$ which is going to result in a linear line with $1 / q_{\mathrm{m}} K_{L}$ as the slope and $1 / q_{\mathrm{m}}$ as the intercept. $K_{F}$ presents the factor of the adsorption capacity and $n$ represents the value of the adsorption intensity factor (1-10) [52]. The 
TABLE 4: Comparing the adsorption capacity of MO on AlgN-CTAB with other adsorbents.

\begin{tabular}{lcc}
\hline Adsorbent & $q_{\max }$ & References \\
\hline Multiwalled carbon nanotubes & 52.86 & {$[54]$} \\
Maghemite/chitosan of nanocomposite film & 29.41 & 89.29 \\
Cross-linked chitosan & 33.00 & {$[55]$} \\
Chitosan/alumina composite & 30.38 & {$[37]$} \\
Fe-La oxide-coloaded MgO (Fe-La/MgO) nanosheets & 50.40 & {$[56]$} \\
Modified wheat straw 3.0 & 66.09 & [57] \\
m-CS/Y-Fe $\mathrm{O}_{3} / \mathrm{MWCNTs}$ & 76.48 & This research \\
AlgN-CTAB
\end{tabular}

graph of $\log q_{\mathrm{e}}$ against $\log C_{\mathrm{e}}$ will yield $K_{F}$ and the exponent $n$. Furthermore, a constant linked to the adsorption energy is presented by $\varepsilon_{\mathrm{DR}}$ (the Polanyi potential), the isotherm constants of D-R are displayed by $q_{\mathrm{DR}}\left(\mathrm{mgg}^{-1}\right)$ and $B_{\mathrm{DR}}\left(\mathrm{mol}^{2} \mathrm{~kJ}^{-2}\right)$, serially, the Temkin constant linked to the heat adsorption is presented by $b_{\mathrm{Te}}\left(\mathrm{J} \mathrm{mol}^{-1}\right), R$ belongs to the gas constant $\left(8.314 \mathrm{~kJ} \mathrm{~mol}^{-1}\right)$, the equilibrium binding constant is written by $K_{\mathrm{Te}}\left(\mathrm{Lg}^{-1}\right)$, and the absolute temperature is expressed by $T(\mathrm{~K})$.

Table 3 explains that in accord with the regression coefficient data $\left(R^{2}\right)$ of each MO adsorption isotherm model by AlgN and AlgN-CTAB, the MO adsorption process tends to follow the AIML and AIMDR pattern compared to AIMF and AIMT. In both adsorption isotherm models, the value of $R^{2}$ is close to 1 . However, when viewed from the RMSE and $\chi^{2}$ values, the AIMDR has a smaller value than the AIMF. In addition, in Figure 10, it may be concluded that the plot of the relationship between adsorbed $\mathrm{MO}$ to $[\mathrm{MO}]_{\mathrm{o}}$ estimated by the AIMDR equation $\left(q_{\text {cal-DR }}\right)$ is relative to the experimental results $\left(q_{\text {exp }}\right)$.

Relatively, it could be deduced that among the dissimilar isotherm patterns, the AIML and AIMDR can satisfy the experimental data more precisely than AIMF and AIMT. Therefore, it can be stated that the MO adsorption by AlgN-CTAB does not fully occur through chemical or physical interactions, but it is a combination of both [53].

3.8. Regeneration of Adsorbent AlgN-CTAB. The ability to reuse adsorbent needs to be known so that the adsorbent can be of practical use without drastic reduction after reuse. For this reason, the ability to reuse AlgN-CTAB adsorption against $\mathrm{MO}$ was performed through a series of repeated adsorption-desorption experiments with $\mathrm{MO}$ as seen in Figure 11. The MO adsorption and desorption results using eluent of $0.1 \mathrm{M}$ hydrochloric acid continually for 4 times did not decrease the \% removal of MO from $80 \%$. The AlgNCTAB adsorbent reuse data can be used as a reference that the adsorbent can be used repeatedly and efficiently in absorbing anionic dyes such as MO in aqueous solutions.

3.9. Comparing the AlgN-CTAB Adsorption Capacity to Other Materials. AlgN-CTAB is an adsorbent which is very effective in absorbing MO dyes. This may be observed from the value of $q_{\max }$ which is relatively large in absorbing MO dye contrasted to other adsorbents as seen in Table 4 . In addition, the process of making AlgN-CTAB is very simple at a relatively low cost. This is one of the considerations for applying this adsorbent in the treatment of waste containing anionic dyes.

\section{Conclusions}

Biomass modification of Nannochloropsis sp. with CTAB surfactant through cation exchange reaction to produce adsorbent Nannochloropsis sp.-cetyltrimethylammonium bromide (AlgN-CTAB) has been successfully carried out. The ability of the AlgN-CTAB adsorbent to absorb methyl orange (MO) anionic dye is optimum at an adsorbent mass $=0.1 \mathrm{~g}, \mathrm{pH}=5$, interaction time $=60 \mathrm{~min}$, and $[\mathrm{MO}]_{\mathrm{o}}=$ $300 \mathrm{mg} \mathrm{L}^{-1}$ producing the number of MO bound $\left(q_{\mathrm{m}}\right)=$ $76.48 \mathrm{mgg}^{-1}$. The MO adsorption kinetic data by AlgNCTAB tend to take the PSO kinetic model, AIML and AIMDR. The results of the adsorption-desorption of $\mathrm{MO}$ by AlgN-CTAB with $0.1 \mathrm{M} \mathrm{HCl}$ eluent with 4 repetitions of the cycle resulted in \% removal of $\mathrm{MO}>80 \%$. Adsorbent modified by Nannochloropsis sp. with CTAB owns a generally great adsorption rate and adsorption capacity confronted to the unmodified biomass. The adsorbent can be used repeatedly to absorb MO anionic dyes in solution.

\section{Data Availability}

The data used to support the findings of this study are available from the corresponding author upon request.

\section{Conflicts of Interest}

The authors declare that they have no conflicts of interest.

\section{Acknowledgments}

This work was funded by Ministry of Education, Culture, Research and Technology (Kemdikbudristek) of the Republic of Indonesia with contract number 120/E4.1/AK.04.PT/2021. The authors thank the Center for Marine Cultivation Development-Lampung (Balai Besar Pengembangan Budi Daya Laut (BBPBDL) Lampung) for participating in this research. 


\section{References}

[1] J. Zhang, S. Zhai, S. Li et al., "Pb(II) removal of $\mathrm{Fe}_{3} \mathrm{O}_{4} @ \mathrm{SiO}_{2}$ $\mathrm{NH}_{2}$ core-shell nanomaterials prepared via a controllable solgel process," Chemical Engineering Journal, vol. 215-216, pp. 461-471, 2013.

[2] S. Buhani, Suharso, I. Aditiya, R. al Kausar, Sumadi, and Rinawati, "Production of a Spirulina sp. algae hybrid with a silica matrix as an effective adsorbent to absorb crystal violet and methylene blue in a solution," Sustainable Environment Research, vol. 29, no. 1, 2019.

[3] F. Li, Y. Kuang, N. Liu, and F. Ge, "Extracellular polymeric substrates of Chlorella vulgaris F1068 weaken stress of cetyltrimethyl ammonium chloride on ammonium uptake," Science of the Total Environment, vol. 661, pp. 678-684, 2019.

[4] J. Liu, Y. Wang, Y. Fang, T. Mwamulima, S. Song, and C. Peng, "Removal of crystal violet and methylene blue from aqueous solutions using the fly ash-based adsorbent materialsupported zero-valent iron," Journal of Molecular Liquids, vol. 250, pp. 468-476, 2018.

[5] U. A. Guler, M. Ersan, E. Tuncel, and F. Dügenci, "Mono and simultaneous removal of crystal violet and safranin dyes from aqueous solutions by HDTMA-modified Spirulina sp.," Process Safety and Environmental Protection, vol. 99, pp. 194206, 2016.

[6] E. Forgacs, T. Cserhati, and G. Oros, "Removal of synthetic dyes from wastewaters: a review," Environment International, vol. 30, no. 7, pp. 953-971, 2004.

[7] V. K. Gupta and A. Rastogi, "Biosorption of lead from aqueous solutions by green algae Spirogyra species: Kinetics and equilibrium studies," Journal of Hazardous Materials, vol. 152, no. 1, pp. 407-414, 2008.

[8] S. Kittappa, S. Pichiah, J. R. Kim, Y. Yoon, S. A. Snyder, and M. Jang, "Magnetised nanocomposite mesoporous silica and its application for effective removal of methylene blue from aqueous solution," Separation and Purification Technology, vol. 153, pp. 67-75, 2015.

[9] S. Dardouri and J. Sghaier, "A comparative study of adsorption and regeneration with different agricultural wastes as adsorbents for the removal of methylene blue from aqueous solution," Chinese Journal of Chemical Engineering, vol. 25, no. 9, pp. 1282-1287, 2017.

[10] S. Mona, A. Kaushik, and C. P. Kaushik, "Waste biomass of Nostoc linckia as adsorbent of crystal violet dye: Optimization based on statistical model," International Biodeterioration \& Biodegradation, vol. 65, no. 3, pp. 513-521, 2011.

[11] C. S. Umpierres, L. T. D. Prola, M. A. Adebayo et al., "Mesoporous $\mathrm{Nb} 2 \mathrm{O} 5 / \mathrm{SiO} 2$ material obtained by sol-gel method and applied as adsorbent of crystal violet dye," Environmental Technology, vol. 38, no. 5, pp. 566-578, 2017.

[12] V. Vaiano, O. Sacco, D. Sannino, and P. Ciambelli, "Nanostructured $\mathrm{N}$-doped $\mathrm{TiO}_{2}$ coated on glass spheres for the photocatalytic removal of organic dyes under UV or visible light irradiation," Applied Catalysis B: Environmental, vol. 170171, pp. 153-161, 2015.

[13] T. Saitoh, M. Saitoh, C. Hattori, and M. Hiraide, "Rapid removal of cationic dyes from water by coprecipitation with aluminum hydroxide and sodium dodecyl sulfate," Journal of Environmental Chemical Engineering, vol. 2, no. 1, pp. 752758, 2014.

[14] C. T. Weber, G. C. Collazzo, M. A. Mazutti, E. L. Foletto, and G. L. Dotto, "Removal of hazardous pharmaceutical dyes by adsorption onto papaya seeds," Water Science and Technology, vol. 70, no. 1, pp. 102-107, 2014.

[15] J. S. Wu, C. H. Liu, K. H. Chu, and S. Y. Suen, "Removal of cationic dye methyl violet $2 \mathrm{~B}$ from water by cation exchange membranes," Journal of Membrane Science, vol. 309, no. 1-2, pp. 239-245, 2008.

[16] J. Shu, R. Liu, H. Wu, Z. Liu, X. Sun, and C. Tao, “Adsorption of methylene blue on modified electrolytic manganese residue: kinetics, isotherm, thermodynamics and mechanism analysis," Journal of the Taiwan Institute of Chemical Engineers, vol. 82, pp. 351-359, 2018.

[17] B. Buhani, S. Suharso, and Z. Sembiring, "Immobilization of Chetoceros sp. microalgae with silica gel through encapsulation technique as adsorbent of $\mathrm{Pb}$ metal from solution," Oriental Journal of Chemistry, vol. 28, no. 1, pp. 271-278, 2012.

[18] R. Angelova, E. Baldikova, K. Pospiskova, Z. Maderova, M. Safarikova, and I. Safarik, "Magnetically modified Sargassum horneri biomass as an adsorbent for organic dye removal," Journal of Cleaner Production, vol. 137, pp. 189-194, 2016.

[19] E. Daneshvar, A. Vazirzadeh, A. Niazi, M. Kousha, M. Naushad, and A. Bhatnagar, "Desorption of Methylene blue dye from brown macroalga: effects of operating parameters, isotherm study and kinetic modeling," Journal of Cleaner Production, vol. 152, pp. 443-453, 2017.

[20] M. Tavana, H. Pahlavanzadeh, and M. J. Zarei, "The novel usage of dead biomass of green algae of Schizomeris leibleinii for biosorption of copper(II) from aqueous solutions: Equilibrium, kinetics and thermodynamics," Journal of Environmental Chemical Engineering, vol. 8, no. 5, article 104272, 2020.

[21] S. Buhani, S. Suharso, F. Luziana, M. Rilyanti, and S. Sumadi, "Production of adsorbent from activated carbon of palm oil shells coated by $\mathrm{Fe}_{3} \mathrm{O}_{4}$ particle to remove crystal violet in water," Desalination and Water Treatment, vol. 171, pp. 281-293, 2019.

[22] T. Sarat Chandra, S. N. Mudliar, S. Vidyashankar et al., "Defatted algal biomass as a non-conventional low-cost adsorbent: surface characterization and methylene blue adsorption characteristics," Bioresource Technology, vol. 184, pp. 395404, 2015.

[23] M. H. Sayadi, N. Salmani, A. Heidari, and M. R. Rezaei, "Biosynthesis of palladium nanoparticle using Spirulina platensis alga extract and its application as adsorbent," Surfaces and Interfaces, vol. 10, pp. 136-143, 2018.

[24] P. Sarwa and S. K. Verma, "Decolourization of Orange G dye by microalgae Acutodesmus obliquues strain PSV2 isolated from textile industrial site," International Journal of Biotechnology applications, vol. 1, no. 4, pp. 247-252, 2013.

[25] A. M. Yusof and N. A. Malek, "Removal of $\mathrm{Cr}(\mathrm{VI})$ and As(V) from aqueous solutions by HDTMA-modified zeolite Y," Journal of Hazardous Materials, vol. 162, no. 2-3, pp. 1019-1024, 2009.

[26] A. Bingol, A. Aslan, and A. Cakici, "Biosorption of chromate anions from aqueous solution by a cationic surfactant- modified lichen (Cladonia rangiformis (L.))," Journal of Hazardous Materials, vol. 161, no. 2-3, pp. 747-752, 2009.

[27] M. Owlad, M. K. Aroua, and W. M. A. Wan Daud, "Hexavalent chromium adsorption on impregnated palm shell activated carbon with polyethyleneimine," Bioresource Technology, vol. 101, no. 14, pp. 5098-5103, 2010.

[28] A. Chen, J. Dong, B. Li et al., "Using a freshwater green alga Chlorella pyrenoidosa to evaluate the biotoxicity of ionic 
liquids with different cations and anions," Ecotoxicology and Environmental Safety, vol. 198, article 110604, 2020.

[29] O. Kaczerewska, R. Martins, J. Figueiredo, S. Loureiro, and J. Tedim, "Environmental behaviour and ecotoxicity of cationic surfactants towards marine organisms," Journal of Hazardous Materials, vol. 392, article 122299, 2020.

[30] F. Buhani, F. Hariyanti, S. Suharso, R. Rinawati, and S. Sumadi, "Magnetized algae-silica hybrid from Porphyridium sp. biomass with $\mathrm{Fe}_{3} \mathrm{O}_{4}$ particle and its application as adsorbent for the removal of methylene blue from aqueous solution," Desalination and Water Treatment, vol. 142, pp. 331-340, 2019.

[31] M. M. Montazer-Rahmati, P. Rabbani, A. Abdolali, and A. R. Keshtkar, "Kinetics and equilibrium studies on biosorption of cadmium, lead, and nickel ions from aqueous solutions by intact and chemically modified brown algae," Journal of Hazardous Materials, vol. 185, no. 1, pp. 401-407, 2011.

[32] S. Peker, S. Yapar, and N. Besün, "Adsorption behavior of a cationic surfactant on montmorillonite," Colloids and Surfaces A: Physicochemical and Engineering Aspects, vol. 104, no. 2-3, pp. 249-257, 1995.

[33] R. Buhani, R. Rinawati, S. Suharso, D. P. Yuliasari, and S. D. Yuwono, "Removal of $\mathrm{Ni}(\mathrm{II}), \mathrm{Cu}(\mathrm{II})$, and $\mathrm{Zn}$ (II) ions from aqueous solution using Tetraselmis sp. biomass modified with silica coated magnetite nanoparticles," Desalination and Water Treatment, vol. 80, pp. 203-213, 2017.

[34] H. Hongping, F. L. Ray, and Z. Jianxi, "Infrared study of HDTMA $^{+}$intercalated montmorillonite," Spectrochimica Acta Part A: Molecular and Biomolecular Spectroscopy, vol. 60, no. 12, pp. 2853-2859, 2004.

[35] Z. Li, W. T. Jiang, and H. Hong, "An FTIR investigation of hexadecyltrimethylammonium intercalation into rectorite," Spectrochimica Acta Part A: Molecular and Biomolecular Spectroscopy, vol. 71, no. 4, pp. 1525-1534, 2008.

[36] A. Gładysz-Płaska, M. Majdan, S. Pikus, and D. Sternik, "Simultaneous adsorption of chromium(VI) and phenol on natural red clay modified by HDTMA," Chemical Engineering \& Technology, vol. 179, no. 1, pp. 140-150, 2012.

[37] R. Huang, Q. Liu, L. Zhang, and B. Yang, "Utilization of crosslinked chitosan/bentonite composite in the removal of methyl orange from aqueous solution," Water Science and Technology, vol. 71, no. 2, pp. 174-182, 2015.

[38] S. Hussain, M. Kamran, S. A. Khan et al., "Adsorption, kinetics and thermodynamics studies of methyl orange dye sequestration through chitosan composites films," International Journal of Biological Macromolecules, vol. 168, pp. 383-394, 2021.

[39] L. Ai, C. Zhang, F. Liao et al., "Removal of methylene blue from aqueous solution with magnetite loaded multi- wall carbon nanotube: Kinetic, isotherm and mechanism analysis," Journal of Hazardous Materials, vol. 198, pp. 282-290, 2011.

[40] S. Buhani, Suharso, and Sumadi, "Adsorption kinetics and isotherm of Cd(II) ion on Nannochloropsis sp biomass imprinted ionic polymer," Desalination, vol. 259, no. 1-3, pp. 140-146, 2010.

[41] Y. D. Liang, Y. J. He, T. T. Wang, and L. H. Lei, “Adsorptive removal of gentian violet from aqueous solution using $\mathrm{CoFe}_{2} \mathrm{O}_{4}$ /activated carbon magnetic composite," Journal of Water Process Engineering, vol. 27, pp. 77-88, 2019.

[42] A. H. AbdEl-Salam, H. A. Ewais, and A. S. Basaleh, "Silver nanoparticles immobilised on the activated carbon as efficient adsorbent for removal of crystal violet dye from aqueous solu- tions. A kinetic study," Journal of Molecular Liquids, vol. 248, pp. 833-841, 2017.

[43] M. Dogan, H. Abak, and M. Alkan, “Adsorption of methylene blue onto hazelnut shell: kinetics, mechanism and activation parameters," Journal of Hazardous Materials, vol. 164, no. 1, pp. 172-181, 2009.

[44] X. Jing, Y. Cao, X. Zhang, D. Wang, X. Wu, and H. Xu, "Biosorption of $\mathrm{Cr}(\mathrm{VI})$ from simulated wastewater using a cationic surfactant modified spent mushroom," Desalination, vol. 269, no. 1-3, pp. 120-127, 2011.

[45] H. Ebadollahzadeh and M. Zabihi, "Competitive adsorption of methylene blue and $\mathrm{Pb}$ (II) ions on the nano-magnetic activated carbon and alumina," Materials Chemistry and Physics, vol. 248, article 122893, 2020.

[46] D. Onyancha, W. Mavura, J. C. Ngila, P. Ongoma, and J. Chacha, "Studies of chromium removal from tannery wastewaters by algae biosorbents, Spirogyra condensata and Rhizoclonium hieroglyphicum," Journal of Hazardous Materials, vol. 158, no. 2-3, pp. 605-614, 2008.

[47] N. Atar, A. Olgun, and S. Wang, "Adsorption of cadmium (II) and zinc (II) on boron enrichment process waste in aqueous solutions: batch and fixed-bed system studies," Chemical Engineering Journal, vol. 192, pp. 1-7, 2012.

[48] X. Xin, Q. Wei, J. Yang et al., "Highly efficient removal of heavy metal ions by amine-functionalized mesoporous $\mathrm{Fe}_{3} \mathrm{O}_{4}$ nanoparticles," Chemical Engineering Journal, vol. 184, pp. 132-140, 2012.

[49] M. Larraza, M. López-Gónzalez, G. Corrales, and G. Marcelo, "Hybrid materials: Magnetite-Polyethylenimine-Montmorillonite, as magnetic adsorbents for $\mathrm{Cr}(\mathrm{VI})$ water treatment," Journal of Colloid and Interface Science, vol. 385, no. 1, pp. 24-33, 2012.

[50] Y. Shao, L. Zhou, C. Bao, J. Ma, M. Liu, and F. Wang, "Magnetic responsive metal-organic frameworks nanosphere with coreshell structure for highly efficient removal of methylene blue," Chemical Engineering Journal, vol. 283, pp. 1127-1136, 2016.

[51] S. H. Asl, M. Ahmadi, M. Ghiasvand, A. Tardast, and R. Katal, "Artificial neural network (ANN) approach for modeling of $\mathrm{Cr}(\mathrm{VI})$ adsorption from aqueous solution by zeolite prepared from raw fly ash (ZFA)," Journal of Industrial and Engineering Chemistry, vol. 19, no. 3, pp. 1044-1055, 2013.

[52] Y. S. Ho, J. F. Porter, and G. McKay, "Equilibrium isotherm studies for the sorption of divalent metal ions onto peat: copper, nickel, and lead single component systems," Water, Air and Soil Pollution, vol. 141, no. 1/4, pp. 1-33, 2002.

[53] S. H. Dhawane, A. A. Khan, K. Singh, A. Tripathi, R. Hasda, and G. Halder, "Insight into optimization, isotherm, kinetics, and thermodynamics of fluoride adsorption onto activated alumina," Environmental Progress \& Sustainable Energy, vol. 37, no. 2, pp. 766-776, 2018.

[54] Y. Yao, H. Bing, X. Feifei, and C. Xiaofeng, "Equilibrium and kinetic studies of methyl orange adsorption on multiwalled carbon nanotubes," Chemical Engineering Journal, vol. 170, no. 1, pp. 82-89, 2011.

[55] R. Jiang, Y. Q. Fu, H. Y. Zhu, J. Yao, and L. Xiao, "Removal of methyl orange from aqueous solutions by magnetic maghemite/chitosan nanocomposite films: adsorption kinetics and equilibrium," Journal of Applied Polymer Science, vol. 125, no. S2, pp. E540-E549, 2012.

[56] J. Zhang, Q. Zhou, and L. Ou, "Kinetic, isotherm, and thermodynamic studies of the adsorption of methyl orange from 
aqueous solution by chitosan/alumina composite," Journal of Environmental Chemical Engineering, vol. 57, no. 2, pp. 412419, 2012.

[57] X. Sun, Y. Zhou, and X. Zheng, "Comparison of adsorption behaviors of Fe-La oxides co-loaded $\mathrm{MgO}$ nanosheets for the removal of methyl orange and phosphate in single and binary systems," Journal of Environmental Chemical Engineering, vol. 8, no. 5, article 104252, 2020.

[58] Y. Su, Y. Jiao, C. Dou, and R. Han, "Biosorption of methyl orange from aqueous solutions using cationic surfactant modified wheat straw in batch mode," Desalination and Water Treatment, vol. 52, no. 31-33, pp. 6145-6155, 2014.

[59] H. Y. Zhu, R. Jiang, L. Xiao, and G. M. Zeng, "Preparation, characterization, adsorption kinetics and thermodynamics of novel magnetic chitosan enwrapping nanosized $\gamma-\mathrm{Fe}_{2} \mathrm{O}_{3}$ and multi-walled carbon nanotubes with enhanced adsorption properties for methyl orange," Bioresource Technology, vol. 101, no. 14, pp. 5063-5069, 2010. 